\section{Caracterização dos casos de violência contra a mulher atendidos em três serviços na cidade de Uberlândia, Minas Gerais, Brasil}

\author{
Violence against women: analysis of cases treated \\ at three services in the city of Uberlândia, \\ Minas Gerais State, Brazil
}

\author{
${ }^{1}$ Faculdade de Medicina, \\ Universidade Federal de \\ Uberlândia, Uberlândia, \\ Brasil. \\ Correspondência \\ M. V. Garcia \\ Programa de Pós-graduação \\ em Ciências da Saúde \\ Faculdade de Medicina, \\ Universidade Federal de \\ Uberlândia. \\ Av. Cesário Alvim 4583, \\ apto. 102, Uberlândia, $M G$ \\ 38405-186, Brasil. \\ mariluciagarcia@yahoo.com.br
}

\begin{abstract}
This study analyzes epidemiological and clinical aspects of violence against women, using three data sources: medical records at the University Hospital in Uberlândia, Minas Gerais State, Brazil; treatment forms from the nongovernmental organization SOS Action for Women and Families; forensic reports on bodily injuries and autopsies from the Medical Examiner's Office. At the University Hospital and Medical Examiner's Office, the records related mainly to physical aggression, with no reference to psychological abuse in the medical charts or forensic reports, revealing that in primary health care services, such violence is only identified through post-aggression interviews with victims. Records at the nongovernmental organization referred mainly to psychological and physical abuse. The three sources showed little reference to sexual violence, corroborating data from the literature on this issue's invisibility, especially conjugal sexual violence suffered by women that seek treatment at these services. According to the current study's findings, the types of violence against women recorded at these three public health and social services differ according to the specific characteristics of the services they provide.
\end{abstract}

Violence Against Women; Aggression; Health Services
Marilúcia Vieira Garcia ${ }^{1}$

Lindioneza Adriano Ribeiro 1

Miguel Tanús Jorge 1

Gustavo Resende Pereira ${ }^{1}$

Alexandra Pires Resende 1

\section{Introdução}

A violência contra o ser humano é um dos eventos bioéticos de maior relevância, pois, além dos danos físicos e psicológicos que ocasiona, necessita de um grande número de ações para a sua prevenção e tratamento 1 . Está presente na vida da maioria das pessoas, de todas as idades, em graus variados, sem distinção de raça, credo, sexo, cultura e classe social 2,3 .

Apresenta-se de forma diferente entre homens e mulheres 3,4. Enquanto a violência cometida contra os homens ocorre, sobretudo, nos espaços públicos e é praticada por alguém do mesmo sexo, aquela contra a mulher ocorre principalmente dentro do seu próprio lar e seu agressor costuma ser do sexo masculino e, muitas vezes, é ou foi uma pessoa íntima 3,5.

Considera-se que a violência praticada pelo parceiro íntimo constitui-se na forma prevalente de violência doméstica contra a mulher 3,6,7. É, muitas vezes, entendida como um fenômeno cultural, fazendo parte dos costumes e normas da sociedade que a aceita como uma forma de ação disciplinar praticada pelo pai em relação à esposa e filhas ${ }^{8}$. Assim, esse desrespeito à dignidade das mulheres tem conivência da sociedade, além de ser facilitado pela impunidade dos agressores 9 .

A Lei $n^{\circ}$. 11.340/2006 10 criou mecanismos para coibir a violência doméstica e familiar contra a mulher e, conceitua a violência física como 
"qualquer conduta que ofenda a integridade ou saúde corporal"; a violência psicológica como "qualquer conduta que cause dano emocional e diminuição da auto-estima, que prejudique e perturbe o pleno desenvolvimento ou que vise a degradar ou controlar suas ações, comportamentos, crenças e decisões, mediante ameaça, constrangimento, humilhação, manipulação, isolamento, vigilância constante, perseguição contumaz, insulto, chantagem, ridicularização, exploração e limitação do direito de ir e vir, ou qualquer outro meio que lhe cause prejuízo à saúde psicológica e à autodeterminação"; a violência sexual como "qualquer conduta que a constranja a presenciar, a manter ou a participar de relação sexual não desejada, mediante intimidação, ameaça, coação ou uso da força; que a induza a comercializar ou utilizar, de qualquer modo, a sua sexualidade, que a impeça de usar qualquer método contraceptivo ou que a force ao matrimônio, à gravidez, ao aborto ou à prostituição, mediante coação, chantagem, suborno ou manipulação; ou que limite ou anule o exercício de seus direitos sexuais e reprodutivos"; a violência patrimonial como "qualquer conduta ilegítima que configure perda, retenção, subtração, destruição parcial ou total de objetos, instrumentos de trabalho, documentos pessoais, bens, valores e direitos ou recursos econômicos, incluindo os destinados a satisfazer suas necessidades"; a violência moral como "qualquer conduta que configure calúnia, difamação ou injúria”. Alguns autores 6,11,12,13 evidenciam a violência verbal, conceituando-a isoladamente, caracterizada por xingamentos, ofensas, ameaças e injúrias, enquanto que, na referida lei este tipo de violência está inserido no contexto da violência moral.

Segundo Minayo 14, a violência provoca conseqüências na qualidade de vida e exige atenção e cuidado dos serviços de saúde em virtude das lesões físicas, psíquicas e morais.

No Brasil, cerca de um terço das internações em unidades de emergência é conseqüência de violência 15 , e a necessidade de internação em diversos casos de violência contra a mulher revela a gravidade das agressões a que a mulher é acometida. A violência doméstica é a causa de $50 \%$ dos homicídios de mulheres 16 , que representam o último grau de uma escala de violência conjugal, que muitas vezes se inicia com o abuso psicológico ${ }^{9}$.

O objetivo do presente estudo é caracterizar aspectos epidemiológicos e clínicos das violências física, sexual, psicológica e verbal contra a mulher em Uberlândia, Minas Gerais, Brasil.

\section{Métodos}

Os dados referentes às agressões contra mulheres com 18 anos de idade ou mais, residentes em Uberlândia, foram obtidos em três fontes distintas: 614 atendimentos médicos no Hospital de Clínicas de Uberlândia da Universidade Federal de Uberlândia (HCU-UFU) nos anos de 2001 a 2003; 1.138 laudos de perícia de lesões corporais e 25 laudos de necropsias, realizados no Posto Médico Legal (PML) nos anos de 2002 e 2003; e 884 fichas de atendimentos às mulheres vítimas de violências realizados na organização nãogovernamental SOS Ação Mulher Família (ONG SOS Mulher) nos anos de 2001 a 2003. Exceto nos casos de óbito, não houve identificação nominal dessas mulheres, existindo então, a possibilidade de uma mesma vítima ter sido atendida em mais de um lugar.

Os tipos de violência evidenciados em cada fonte desta pesquisa estão de acordo com a disponibilidade das informações oferecidas por esses serviços, mantendo-se a classificação própria de cada instituição.

O HCU é um hospital público, universitário, conveniado ao Sistema Único de Saúde (SUS) como centro terciário de referência em saúde 17 . Com base nos dados obtidos no HCU foram analisadas as características das lesões (tipos de violências e lesões mais freqüentes; regiões anatômicas acometidas) e a evolução clínica das pacientes (alta, internação, retorno ambulatorial e óbitos).

No PML foram analisados os tipos de violências, as lesões mais freqüentes, as regiões anatômicas acometidas e a ocorrência de óbito.

A ONG SOS Mulher é uma organização de utilidade pública e tem como missão prestar atendimento e apoio às famílias que vivenciam a violência conjugal e intrafamiliar por meio de atuação interprofissional 18. Os dados obtidos foram: as características da vítima (idade, estado civil, escolaridade, profissão/ocupação), do agressor (idade, relação de parentesco com a vítima, escolaridade, profissão/ocupação) e da violência (tipos mais freqüentes, local de ocorrência, causas referidas pelas vítimas).

Este estudo foi aprovado pelo Comitê de Ética em Pesquisa da UFU.

\section{Resultados}

Nos atendimentos do HCU e PML, a maioria dos episódios de violência contra as mulheres foi agressões físicas, enquanto que, naquelas atendidas na ONG SOS Mulher predominou tanto 
este tipo de agressão (35,9\%) quanto a violência psicológica (36,2\%) (Tabela 1).

Nos casos atendidos na ONG SOS Mulher, $70 \%$ das vítimas encontram-se na faixa etária de 18 a 39 anos, a metade declarou-se amasiada, e entre as que informaram o nível de escolaridade, mais da metade referiu ter cursado o ensino fundamental incompleto (52,6\%). Daquelas em que se obteve informação sobre a profissão, $41 \%$ eram domésticas ou do lar (Tabela 2). Os agressores eram predominantemente do sexo masculino (97,6\%), tinham de 20 a 49 anos de idade $(87,8 \%)$, e dos casos em que se conseguiu a informação, $57,7 \%$ não haviam concluído o primeiro grau. Suas principais profissões/ocupações eram pedreiros/serventes $(14,2 \%)$ e motoristas $(9,2 \%)$ (Tabela 2). As agressões ocorreram com maior freqüência no lar (85\%) e foram perpetradas, sobretudo, pelos amásios/ex-amásios (50,2\%). As causas de agressão, segundo as vítimas, foram principalmente os vícios e o ciúme $(36,9 \%$ e $19,9 \%$, respectivamente) e a esperança de melhorar o relacionamento conjugal foi o principal motivo (33,8\%) referido pelas mulheres para continuarem convivendo com seus companheiros após as agressões sofridas (Tabela 3).

Nos atendimentos realizados no HCU e no PML as lesões foram provocadas principalmente por agentes mecânicos (96,9\% e 90,4\%, respectivamente), causando, sobretudo, feridas contusas $(62,3 \%$ e $74,8 \%$, respectivamente), atingindo, em especial, cabeça/pescoço $(39,1 \%)$ nos atendi- mentos do HCU, e membros superiores $(35,1 \%)$ nos do PML (Tabela 4).

Das 614 mulheres atendidas no HCU, 515 $(83,9 \%)$ receberam alta logo após o atendimento no pronto-socorro, 83 (13,5\%) foram internadas e $16(2,6 \%)$ foram atendidas somente no ambulatório; $108(17,6 \%)$ foram encaminhadas para retornos em ambulatórios especializados de odontologia buco-maxilo-facial $(20 ; 15,1 \%)$, ortopedia e traumatologia $(19 ; 14,4 \%)$, clínica médica (18; $13,6 \%)$, cirurgia plástica $(9 ; 6,8 \%)$, ginecologia e obstetrícia $(9 ; 6,8 \%)$, oftalmologia $(7 ; 5,3 \%)$, psiquiatria $(5 ; 3,8 \%)$ e outros $(45 ; 34,1 \%)$. Algumas vítimas foram encaminhadas para atendimento em mais de um serviço ou especialidade.

Foram registrados 11 óbitos no HCU e 25 no PML, decorrentes principalmente de ferimentos por arma branca $(36,4 \%$ e $44 \%$, respectivamente) e por arma de fogo $(36,4 \%$ e $20 \%$, respectivamente) (Tabela 5). Além disso, com base nos dados, em diversos casos de agressão nota-se provável intenção do homicídio, por exemplo, nas tentativas de esganadura e sufocação (Tabela 4).

\section{Discussão}

Características específicas dos serviços oferecidos em cada instituição levam às diferentes freqüências das variáveis pesquisadas no HCU, PML e na ONG SOS Mulher, visto serem serviços distintos, com clientela e modalidades de aten-

Tipos de violências sofridas pelas mulheres segundo o local de atendimento. Uberlândia, Minas Gerais, Brasil, 2001 a 2003.

\begin{tabular}{|c|c|c|c|c|c|c|}
\hline \multirow[t]{3}{*}{ Tipos de violências } & \multicolumn{6}{|c|}{ Local de atendimento } \\
\hline & \multicolumn{2}{|c|}{$\mathrm{HCU}$} & \multicolumn{2}{|c|}{ PML } & \multicolumn{2}{|c|}{ ONG SOS Mulher } \\
\hline & $\mathrm{n}$ & $\%$ & $\mathrm{n}$ & $\%$ & $\mathrm{n}$ & $\%$ \\
\hline Física & 603 & 98,2 & 1.116 & 96,0 & 696 & 32,0 \\
\hline Física e sexual & 7 & 1,1 & 26 & 2,2 & 85 & 3,9 \\
\hline Sexual & 4 & 0,7 & 21 & 1,8 & 20 & 1,0 \\
\hline Psicológica & - & - & - & - & 787 & 36,2 \\
\hline Verbal & - & - & - & - & 586 & 26,9 \\
\hline Total * & 614 & 100,0 & 1.163 & 100,0 & $2.174 * \star$ & 100,0 \\
\hline
\end{tabular}

HCU: Hospital de Clínicas de Uberlândia; PML: Posto Médico Legal; ONG SOS Mulher: organização não-governamental SOS Ação Mulher Família.

Fontes: prontuários médicos do HCU (2001 a 2003), laudos de exame de corpo delito e de necrópsia do PML (2002 e 2003) e fichas de atendimento da ONG SOS Mulher (2001 a 2003).

* Não houve identificação nominal dessas mulheres, existindo então, a possibilidade de uma mesma vítima ter sido atendida em mais de um lugar;

** Foram 884 mulheres atendidas na ONG SOS Mulher que sofreram 2.174 agressões, pois uma mulher podia ter sofrido mais de um tipo de violência. 
Características sócio-demográficas e etárias das vítimas e dos autores da violência segundo os atendimentos na organização não-governamental SOS Ação Mulher Família (ONG SOS Mulher). Uberlândia, Minas Gerais, Brasil, 2001 a 2003.

\begin{tabular}{|c|c|c|}
\hline Características sócio-demográficas das vítimas e dos autores da violência & $\mathrm{n}$ & $\%$ \\
\hline \multicolumn{3}{|l|}{ Mulheres vítimas de violência } \\
\hline Faixa etária (anos) & 876 & 100,0 \\
\hline $18-19$ & 21 & 2,4 \\
\hline $20-29$ & 317 & 36,2 \\
\hline $30-39$ & 292 & 33,3 \\
\hline $40-49$ & 182 & 20,8 \\
\hline $50-59$ & 51 & 5,8 \\
\hline$\geq 60$ & 13 & 1,5 \\
\hline Estado civil & 860 & 100,0 \\
\hline Amasiada & 433 & 50,3 \\
\hline Casada & 351 & 40,8 \\
\hline Separada/Divorciada & 43 & 5,0 \\
\hline Solteira & 26 & 3,0 \\
\hline Viúva & 7 & 0,9 \\
\hline Escolaridade & 650 & 100,0 \\
\hline Analfabeto/Semi-alfabetizado & 11 & 1,7 \\
\hline Ensino Fundamental incompleto & 331 & 50,9 \\
\hline Ensino Fundamental completo & 106 & 16,3 \\
\hline Ensino Médio incompleto & 30 & 4,6 \\
\hline Ensino Médio completo & 126 & 19,4 \\
\hline Ensino Superior incompleto & 11 & 1,7 \\
\hline Ensino Superior completo & 35 & 5,4 \\
\hline Profissão/Ocupação & 485 & 100,0 \\
\hline Doméstica & 148 & 30,5 \\
\hline Do lar & 51 & 10,5 \\
\hline Serviços gerais & 36 & 7,4 \\
\hline Costureira & 24 & 5,0 \\
\hline Professora & 19 & 3,9 \\
\hline Auxiliar de cozinha & 16 & 3,3 \\
\hline Vendedora & 15 & 3,1 \\
\hline Secretária & 14 & 2,9 \\
\hline Comerciante & 13 & 2,7 \\
\hline Atendente de telemarketing & 12 & 2,5 \\
\hline Manicure/Cabeleireira & 10 & 2,1 \\
\hline Auxiliar administrativo & 8 & 1,6 \\
\hline Outras & 119 & 24,5 \\
\hline
\end{tabular}

(continua)

dimentos diferentes. A predominância de casos de violência física no atendimento hospitalar foi também referida por outros autores 6,7 em pesquisas realizadas em instituições hospitalares por ser a violência que mais freqüentemente provoca lesões e requer atendimento médico, enquanto que, a elevada ocorrência da violência psicológica na ONG SOS Mulher constitui um achado freqüente em pesquisas realizadas em instituições sociais de atenção à mulher 17,18. Estudo de Deslandes et al. 6, desenvolvido em dois hospi- tais públicos de referência do Município do Rio de Janeiro, Brasil, mostrou que das 72 mulheres atendidas, 70,4\% sofreram agressões por espancamentos. Schraiber et al. 7, em uma pesquisa com entrevista padronizada a mulheres de 15 a 49 anos atendidas em uma unidade de atenção primária à saúde, encontraram que $44,4 \%$ delas relataram pelo menos um episódio de violência física na vida adulta. No entanto, mesmo com esses percentuais, os autores chamam a atenção para o silêncio e a invisibilidade que envolve a 


\begin{tabular}{|c|c|c|}
\hline Características sócio-demográficas das vítimas e dos autores da violência & $\mathrm{n}$ & $\%$ \\
\hline \multicolumn{3}{|l|}{ Autores da violência } \\
\hline Faixa etária (anos) & 786 & 100,0 \\
\hline $14-19$ & 8 & 1,0 \\
\hline $20-29$ & 176 & 22,4 \\
\hline $30-39$ & 299 & 38,1 \\
\hline $40-49$ & 215 & 27,3 \\
\hline $50-59$ & 68 & 8,7 \\
\hline$\geq 60$ & 20 & 2,5 \\
\hline Escolaridade & 650 & 100,0 \\
\hline Analfabeto/Semi-alfabetizado & 26 & 4,0 \\
\hline Ensino Fundamental incompleto & 349 & 53,7 \\
\hline Ensino Fundamental completo & 121 & 18,6 \\
\hline Ensino Médio incompleto & 27 & 4,2 \\
\hline Ensino Médio completo & 102 & 15,7 \\
\hline Ensino Superior incompleto & 4 & 0,6 \\
\hline Ensino Superior completo & 21 & 3,2 \\
\hline Profissão/Ocupação & 677 & 100,0 \\
\hline Pedreiro/Servente & 96 & 14,2 \\
\hline Motorista & 62 & 9,2 \\
\hline Serviços gerais & 43 & 6,4 \\
\hline Vendedor & 32 & 4,7 \\
\hline Mecânico & 30 & 4,4 \\
\hline Comerciante & 25 & 3,7 \\
\hline Aposentado & 22 & 3,2 \\
\hline Autônomo & 22 & 3,2 \\
\hline Pintor & 22 & 3,2 \\
\hline Vigilante & 22 & 3,2 \\
\hline Eletricista & 13 & 1,9 \\
\hline Auxiliar de produção & 12 & 1,8 \\
\hline Operador de máquina & 12 & 1,8 \\
\hline Policial & 12 & 1,8 \\
\hline Outras & 252 & 37,3 \\
\hline
\end{tabular}

HCU: Hospital de Clínicas de Uberlândia; PML: Posto Médico Legal; ONG SOS Mulher: organização não-governamental SOS Ação Mulher Família.

Fontes: prontuários médicos do HCU (2001 a 2003), laudos de exame de corpo delito e de necrópsia do PML (2002 e 2003) e fichas de atendimento da ONG SOS Mulher (2001 a 2003).

* Não houve identificação nominal dessas mulheres, existindo então, a possibilidade de uma mesma vítima ter sido atendida em mais de um lugar;

** Foram 884 mulheres atendidas na ONG SOS Mulher que sofreram 2.174 agressões, pois uma mulher podia ter sofrido mais de um tipo de violência.

questão da violência contra a mulher que muitas vezes não é detectada no setor saúde pela dificuldade em se falar e tratar do assunto, tanto por parte das mulheres agredidas quanto por parte dos profissionais 8 .

A ausência de alusão à violência psicológica nos prontuários médicos e nos laudos mostra que em serviços de atenção primária à saúde este tipo de violência somente é evidenciado em pesquisas pós-entrevistas com as vítimas.
A elevada ocorrência da violência psicológica encontrada na ONG SOS Mulher corrobora o estudo realizado por Galvão \& Andrade 19 no Centro de Atendimento à Mulher no Município de Londrina, Paraná, Brasil, que oferece atendimentos jurídicos, sociais e psicológicos às mulheres vítimas de violência, onde os autores encontraram maior prevalência das violências psicológica/emocional $(56,4 \%)$ e física (32,1\%). Também, a elevada ocorrência de violência verbal encontrada nos atendimentos da ONG SOS Mulher 
Fatores relacionados com os episódios de violência atribuídos pelas vítimas segundo os atendimentos na organização não-governamental SOS Ação Mulher Família (ONG SOS Mulher). Uberlândia, Minas Gerais, Brasil, 2001 a 2003.

\begin{tabular}{|c|c|c|}
\hline Fatores circunstanciais dos episódios de violência & $\mathbf{n}$ & $\%$ \\
\hline Local de ocorrência das violências & 562 & 100,0 \\
\hline Lar & 478 & 85,0 \\
\hline "Qualquer lugar" & 46 & 8,2 \\
\hline Via pública & 29 & 5,2 \\
\hline Outros & 9 & 1,6 \\
\hline Relação de parentesco entre o autor da violência e a vítima & 887 & 100,0 \\
\hline Amásio/Ex-amásio & 445 & 50,2 \\
\hline Cônjuge/Ex-cônjuge & 363 & 40,9 \\
\hline Filhos & 20 & 2,2 \\
\hline Namorado/Ex-namorado & 16 & 1,8 \\
\hline Outros parentes & 15 & 1,7 \\
\hline Conhecidos & 7 & 0,8 \\
\hline Vizinhos & 7 & 0,8 \\
\hline Desconhecidos & 6 & 0,7 \\
\hline Irmão & 5 & 0,6 \\
\hline Pai/Mãe & 3 & 0,3 \\
\hline Motivos referidos pelas vítimas para a violência & 1.031 & 100,0 \\
\hline Vícios & 380 & 36,9 \\
\hline Ciúmes & 205 & 19,9 \\
\hline Raiva/Revolta & 154 & 15,0 \\
\hline Infidelidade & 132 & 12,8 \\
\hline Situação financeira & 61 & 5,9 \\
\hline Recusa sexual & 27 & 2,6 \\
\hline Filhos & 15 & 1,4 \\
\hline Outros & 57 & 5,5 \\
\hline \multicolumn{3}{|l|}{ Motivos pelos quais as vítimas continuaram } \\
\hline convivendo com o autor da violência após a agressão sofrida & 598 & 100,0 \\
\hline Esperança de melhorar o relacionamento & 202 & 33,8 \\
\hline Medo das ameaças & 141 & 23,6 \\
\hline Situação financeira & 84 & 14,0 \\
\hline Filhos & 55 & 9,2 \\
\hline Outros & 116 & 19,4 \\
\hline
\end{tabular}

confirma os dados obtidos por outros autores como Adeodato et al. ${ }^{13}$, que analisando a qualidade de vida e depressão em mulheres atendidas na Delegacia do Ceará, Brasil, observaram que a maioria sofreu agressões verbais e físicas (83\%). Deslandes et al. 6 também verificaram a ocorrência da agressão verbal, base de qualquer agressão, como fator que precede a violência física. Entretanto, segundo esses autores, a violência verbal é banalizada e raramente reconhecida, tornando-se talvez a mais invisível de todos os tipos de violência. Schumacher \& Leonard 20 , analisando desajustes conjugais, agressão verbal e física durante os dois primeiros anos de união conjugal de 634 casais, verificaram que a agressão verbal precede e acompanha a violência física fazendo parte da rotina de convivência. Hasselmann \& Reichenheim 12 referem que casais que tentam resolver seus conflitos por meio das ofensas verbais são os que mais praticam a agressão física, ao contrário daqueles que optam pelo diálogo.

A baixa ocorrência de violência sexual encontrada no presente estudo corrobora com a invisibilidade da questão, já apresentada em diversos estudos, principalmente da violência sexual conjugal sofrida pelas mulheres que buscam ajuda nesses serviços. Essa baixa porcentagem pode ser explicada pelo fato de que a verdadeira ocorrência dessa violência é desconhecida, sendo uma das condições de maior subnotificação e sub-re- 
Tipos de lesões e regiões anatômicas acometidas segundo o local de atendimento. Uberlândia, Minas Gerais, Brasil, 2001 a 2003

\begin{tabular}{|c|c|c|c|c|}
\hline \multirow[t]{3}{*}{ Tipos de lesões/Regiões anatômicas acometidas } & \multicolumn{4}{|c|}{ Local de atendimento } \\
\hline & \multicolumn{2}{|c|}{$\mathrm{HCU}$} & \multicolumn{2}{|c|}{ PML } \\
\hline & $\mathbf{n}$ & $\%$ & $\mathbf{n}$ & $\%$ \\
\hline Lesões causadas por agentes mecânicos & 610 & & 1.269 & \\
\hline \multicolumn{5}{|l|}{ Feridas fechadas } \\
\hline Contusas & 392 & 62,3 & 1.049 & 74,8 \\
\hline \multicolumn{5}{|l|}{ Feridas abertas } \\
\hline Incisas & 26 & 4,1 & 87 & 6,2 \\
\hline Corto-contusas & 137 & 21,8 & 63 & 4,5 \\
\hline Puntiformes & 3 & 0,5 & 1 & 0,1 \\
\hline Pérfuro-incisas & 19 & 3,0 & 61 & 4,3 \\
\hline Pérfuro-contusas & 33 & 5,2 & 8 & 0,5 \\
\hline Lesões causadas por agentes físicos & 9 & & 4 & \\
\hline Queimadura (calor) & 9 & 1,4 & 4 & 0,3 \\
\hline Lesões causadas por agentes físico-químicos (asfixias mecânicas) & 10 & & 130 & \\
\hline Enforcamento *,** & - & - & 4 & 0,30 \\
\hline Esganadura * & - & - & 1 & 0,07 \\
\hline Estrangulamento * & - & - & 2 & 0,14 \\
\hline Sufocação * & - & - & 1 & 0,07 \\
\hline Tentativa de esganadura & 9 & 1,5 & 120 & 8,55 \\
\hline Tentativa de sufocação & 1 & 0,2 & 2 & 0,14 \\
\hline Regiões anatômicas acometidas & 1.226 & & 2.065 & \\
\hline Cabeça/Pescoço & 480 & 39,1 & 592 & 28,7 \\
\hline Membros superiores & 354 & 28,9 & 725 & 35,1 \\
\hline Membros inferiores & 140 & 11,4 & 391 & 18,9 \\
\hline Tronco & 252 & 20,5 & 357 & 17,3 \\
\hline
\end{tabular}

HCU: Hospital de Clínicas de Uberlândia; PML: Posto Médico Legal.

Fontes: prontuários médicos do HCU (2001 a 2003) e laudos de exame de corpo delito e de necrópsia do PML (2002 e 2003).

Exceto nos casos de óbitos, não houve a identificação nominal dessas mulheres, existindo então, a possibilidade de uma

mesma vítima ter sido atendida em mais de um lugar.

* Óbitos;

** Nos casos de enforcamento não se pôde caracterizar se foi homicídio ou suicídio.

gistro em todo o mundo 21,22. Segundo Oshikata et al. 23, uma das causas que contribui para a baixa freqüência de denúncias é que a maioria das agressões ocorre em ambientes familiares ou são praticadas por pessoas conhecidas, com vínculo sentimental ou hierárquico entre agressores e vítimas, e estas nem sempre denunciam ou procuram atendimento médico, ainda que a violência se repita por meses ou anos. Dantas-Berger \& Giffin 24 , em um estudo qualitativo sobre violência sexual, realizaram entrevistas com mulheres entre 25 e 51 anos de idade que denunciaram violência conjugal no Centro Integrado de Atendimento à Mulher no Rio de Janeiro, e também referem que ocorre subnotificação nas denúncias de violência sexual praticada por parceiros íntimos no âmbito doméstico. Segundo os auto- res, o sexo vaginal forçado no casamento poucas vezes é reconhecido como violência, parecendo enquadrar-se socialmente e sexualmente como “normal” na relação. Diniz \& D'Oliveira 25, em um estudo de revisão da literatura, relatam que $40 \%$ das mulheres declararam ter vivenciado uma relação sexual não consentida com seu parceiro, sendo o estupro referido por apenas $12 \%$ delas. Saffioti \& Almeida, 26 acrescentam que a violência sexual desconhece fronteiras, ocorrendo em populações de diferentes desenvolvimentos sociais e econômicos, no espaço público ou privado, e em qualquer etapa da vida da mulher, e esta violência acarreta um complexo problema de saúde pública, pois, além dos danos psicológicos, do risco de contrair doenças sexualmente transmissíveis, verifica-se a possibilidade da 
Tabela 5

Causas de óbitos resultantes das agressões segundo o local de atendimento. Uberlândia, Minas Gerais, Brasil, 2001 a 2003

\begin{tabular}{lcccc}
\hline Causas de óbitos & \multicolumn{4}{c}{ Local de atendimento } \\
& n & HCU & PML & $\%$ \\
\hline Arma branca & 4 & 36,4 & 11 & 44,0 \\
Arma de fogo & 4 & 36,4 & 5 & 20,0 \\
Instrumento contundente * & 2 & 18,2 & 1 & 4,0 \\
Enforcamento ** & - & - & 4 & 16,0 \\
Esganadura & - & - & 1 & 4,0 \\
Estrangulamento & - & - & 2 & 8,0 \\
Sufocação & - & - & 1 & 4,0 \\
Queimadura & 1 & 9,0 & - & - \\
Total & 11 & 100,0 & 25 & 100,0 \\
\hline
\end{tabular}

HCU: Hospital de Clínicas de Uberlândia; PML: Posto Médico Legal.

Fontes: prontuários médicos do HCU (2001 a 2003) e laudos de exame de corpo delito e de necrópsia do PML (2002 e 2003).

* Força física direta (murro) sem uso de instrumento e/ou uso de instrumento não pérfurocortante;

** Nos casos de enforcamento não se pôde caracterizar se foi homicídio ou suicídio.

ocorrência de gravidez pós-estupro e de lesões genitais e não-genitais 2 .

O predomínio de mulheres vítimas de agressão na faixa etária de 18 a 39 anos, encontrada no presente estudo, é concordante com o apresentado por diversas pesquisas 6,27,28,29. Guerra 27 refere que em virtude dos padrões culturais brasileiros nessa faixa etária o corpo é belo e desperta atenção, o que poderia provocar nos homens inseguranças e práticas autoritárias violentas, o que explicaria no presente estudo a diminuição da ocorrência de agressão à mulher a partir da quarta década de vida. Já em relação à violência sexual, Oshikata et al. 23 , em estudo prospectivo com 166 mulheres atendidas no Centro de Atenção Integral à Saúde da Mulher da Universidade Estadual de Campinas, São Paulo, Brasil, relatam que mulheres vitimadas sexualmente tinham com maior freqüência menos de 19 anos (42,2\% de 15 a 19 anos e $33,7 \%$ de 20 a 29 anos), revelando que este tipo de violência se apresenta numa faixa etária específica.

Não existe consenso na literatura quanto ao estado civil das vítimas. Alguns autores apontam para a condição de solteiras $6,23,27$, outros para a de amasiadas 28,29 e, outros para a de casadas 13,19. Guerra 27 e Deslandes et al. 6 advertem para a necessidade de apuração dessa variável pois muitas mulheres que convivem com um companheiro declaram-se solteiras, mas quando fazem referência à relação com o agressor os apresentam como maridos e amásios.

As principais profissões/ocupações das vítimas, encontradas no presente estudo, corroboram dados apresentados por Guerra 27 que mostram a predominância da profissão de empregada doméstica (59\%). Essa mesma autora chama a atenção para a possibilidade de confusão com os termos doméstica e do lar, tanto por parte das mulheres vítimas quanto pelos profissionais que registram a queixa, deixando dúvidas se a mulher trabalha em sua casa ou para outras pessoas. Porto 30 e Schraiber et al. 7 apontam que grande parte das vítimas declara-se do lar. Esses autores advertem para o cuidado de não se efetuar conclusões precipitadas, pois a violência também ocorre nas classes sociais média e alta, e estas, segundo Marques 29 , por receio de escândalos, utilizam-se de serviços particulares. Segundo Barsted 3, a invisibilidade desse fenômeno nessas classes sociais e as estratégias das mulheres para lidarem com essa violência fazem com que suas características econômicas e culturais não estejam presentes no perfil das vítimas, ficando evidenciadas na mídia somente em situações extremas, quando ocorrem homicídios praticados por maridos ou companheiros.

O baixo nível de escolaridade das mulheres vítimas de violências, encontrado na presente pesquisa, confirma dados da literatura 7,27,29. Estudo de Kronbauer \& Meneghel 31, com 251 mulheres vítimas de violência entre 18 e 49 anos, atendidas em uma unidade básica de saúde de Porto Alegre, Rio Grande do Sul, Brasil, mostrou associação entre baixa escolaridade e violência. Adeodato et al. 13 acrescentam que a escolaridade da mulher agredida evidencia em média seis anos de estudo, embora Sant'Anna 32 afirme que as agressões ocorrem com mulheres de todos os níveis educacionais. Estudo de Drezzet 21, com vítimas atendidas no Serviço de Atenção Integral à Mulher Sexualmente Vitimada, em São Paulo, também revela que é nítida a condição de baixa escolaridade das mulheres vítimas de violência (40\% não tinham concluído o Ensino Fundamental), porém, o autor adverte que este achado pode estar relacionado à freqüente limitação educacional das pacientes que são atendidas nos serviços públicos de saúde.

O predomínio de agressores do sexo masculino e adultos jovens, conforme dados do presente estudo, corrobora dados da literatura 3,25,33,34. Alguns autores 27,35 discutem as relações desiguais entre homens e mulheres, resultantes das diferenças sexuais presentes no "ser macho" ou "ser fêmea” que levam à subordinação histórica das mulheres e que, ora são atribuídas aos valores patriarcais que atravessam os tempos e se fazem 
ainda tão presentes na vida de muitas, ou ora a um conceitos mais amplos, que são as questões de gênero que refletem a construção social do ser homem e do ser mulher, determinada pela sociedade. Dessa forma, a violência contra a mulher é um exemplo típico de como as desigualdades se manifestam, sendo o agressor principalmente do sexo masculino.

Outros autores 27,29,31 também encontraram que os agressores tinham idade entre 20 e 49 anos. Estudos de Guerra 27 e Marques 29 mostraram predominância de agressores na faixa etária dos 21 aos 40 anos (69\% e 64,6\%, respectivamente).

A baixa escolaridade do agressor corrobora estudo de Marques 29 que encontrou 53,5\% dos agressores com o primeiro grau incompleto e os achados de Guerra 27 em que cerca da metade ocupa cargos que necessitam de pouca escolaridade, tais como os de recepcionista, motorista, garçom, mecânico, porteiro, vendedor e serviços gerais, dentre outros.

A predominância da violência dentro do próprio lar, verificada no presente estudo, confirma dados da literatura 5,6,32. Deslandes et al. 6 apontam em uma pesquisa que $80,3 \%$ das agressões foram praticadas no interior da residência, sendo recorrentes, e os autores acreditam que as agressões são facilitadas pelo fato de transcorrerem na privacidade e sem interferências de outras pessoas. Segundo Guerra 27, o "lar, doce(?) lar" que deveria representar um local seguro para todo cidadão, nem sempre o é para a mulher. Noronha \& Daltro ${ }^{36}$, com base em revisão de artigos sobre violência contra a mulher, publicados no jornal A Tarde no ano de 1989, consideraram que o lar muitas vezes torna-se um espaço perigoso. Também Barsted 3 refere que além do medo da violência no espaço público, que atinge toda a sociedade, as mulheres em especial temem também a violência no espaço privado.

A maior ocorrência de violência perpetrada pelo próprio companheiro, conforme encontrado no presente estudo, também corrobora dados da literatura 3,29,32,37 que apresentam consenso sobre o abuso por parte do marido ou companheiro ser a forma mais comum de violência contra a mulher. Ramirez-Rodriguez \& PatinoGuerra ${ }^{38}$, realizaram entrevistas com 57 mães de alunos de escola primária de Jalisco, México, e observaram que $46 \%$ delas sofriam violência doméstica e em $73 \%$ dos casos o agressor era o esposo. Em pesquisas de base populacional realizadas no mundo, entre $10 \%$ e $69 \%$ das mulheres relataram ter sofrido ao menos algum episódio de violência física pelo parceiro durante a vida 39 . A violência física na vida adulta advinda de um parceiro atinge ao menos uma vez $20 \%$ a $50 \%$ das mulheres no mundo 33 , e o marido aparece como agressor na maioria dos casos 6 . Contudo, Saffioti \& Almeida 26 (p. 36) consideram que "o inimigo da mulher não é especificamente o homem, mas toda uma organização social de gênero, alimentada, reforçada, disseminada não só por homens, mas também por mulheres, ou seja, toda uma cultura de uma sociedade". Quando se trata de violência sexual, especificamente, os desconhecidos são apontados como os principais agressores 23 , mas esta predominância deve ser contextualizada para uma melhor compreensão deste fenômeno, pois nos casos de violência sexual doméstica as vítimas, quer por medo de vingança, sensação de culpa, desconhecimento dos direitos legais e/ou descrédito na justiça, muitas vezes não denunciam 2. Acrescenta-se ainda o vínculo sentimental ou hierárquico entre vítimas e agressores como fatores que contribuem para a ausência de denúncia. Desse modo, entre as notificações sobressaem os registros de casos de violência sexual urbana e provocada por desconhecidos 23 .

Como no presente estudo, outros autores também encontraram que vícios (álcool e outras drogas) e ciúmes são os principais motivos da violência $13,32,40$. A violência conjugal e o estupro têm sido constantemente associados ao abuso de drogas. Guerra 18,27 adverte que embora o álcool possa estar associado à violência familiar, não é o seu responsável básico, atuando como facilitador de situações previamente determinadas. Ademais, segundo a autora, cultura, tipos de família, machismo, situação sócio-econômica e até problemas de saúde são fatores que compõem a base da violência.

Marques 29 mostra, como no presente estudo, que as mulheres continuam na relação violenta por acreditarem que o parceiro possa modificar o comportamento violento, e Adeodato et al. 13 salientam além deste fator citado a existência de filho, a dependência financeira, a paixão e o medo do parceiro como importantes fatores. Galvão \& Andrade 19, juntamente com Saffioti 41, acrescentam ainda o fator emocional.

O predomínio de feridas contusas e cortocontusas, encontrado no presente estudo, está de acordo com os dados de Cardoso 42 que encontrou mais de $40 \%$ das agressões registradas envolvendo golpes, bofetadas, amarração, pancadas, estrangulamento e queimadura dos seios e da genitália, revelando que a mulher é vítima das mais diversas formas de tortura. Day et al. 43, analisando as diversas manifestações de violência doméstica e os diferentes determinantes envolvidos, apontam que os agressores utilizam-se principalmente de objetos corto-contundentes, que muitas vezes, resultam em homicídios e lesões graves. 
A maior ocorrência de agressões atingindo cabeça/pescoço e membros superiores, conforme dados do presente trabalho, confirma vários estudos 6,7,44,45,46. Segundo Garbin et al. ${ }^{44}$, dentre todas as regiões atingidas a de cabeça e pescoço foi a que obteve maior prevalência (30\%), seguida dos membros superiores $(24,4 \%)$. Rezende et al. 46 , estudando os laudos de mulheres vítimas de violência atendidas no IML de Belo Horizonte, Minas Gerais, revelam que as lesões buco-dentais são freqüentes e representam uma grande demanda para os serviços odontológicos de saúde pública. Segundo os autores, no grupo de lesões em tecidos periodontais a avulsão foi responsável por 18,3\% das lesões, tornando as mulheres que sofreram agressão, em geral, deformadas e com a necessidade do uso de prótese e implante ósteo-integrado ou não. Chrcanovic et al. ${ }^{45}$, avaliando fraturas faciais em mulheres atendidas em um hospital público de Belo Horizonte, referem que a violência constitui a segunda causa deste tipo de fratura em mulheres agredidas. Estudo realizado na Inglaterra com 100 mulheres espancadas e acolhidas num abrigo encontrou em 44 delas feridas sangrentas, e em 24, fraturas dentárias 26. Estudo mexicano realizado com 57 mulheres mostrou que as lesões mais observadas na violência física foram os hematomas, seguidos das lesões que requerem alguma sutura 38 . Segundo Deslandes et al. 6, a face é a área preferida pelos agressores e nos casos em que o braço ou mão foram atingidos, na maioria das vezes isto foi devido ao fato da mulher tentar proteger a face. Para Schraiber et al. 7 (p. 476), as agressões nessas regiões, especialmente na face, podem indicar "além de um comportamento de defesa com os braços, o caráter simbólico de humilhação e de agressão à dignidade da pessoa humana de que se revestem os atos de agressão".

Segundo Braga 9, o espancamento de uma parceira íntima pode ser rotineiro, sendo raro que ocorra uma única vez. Com o tempo a violência tende a tornar-se mais freqüente e aumentar em gravidade; as marcas visíveis da violência são tratadas nos serviços de saúde, para, em seguida, as mulheres retornarem ao mesmo ciclo de espancamento e abusos que muitas vezes resultam em homicídios ou suicídios.

Os serviços e especialidades médicas mais envolvidas nos atendimentos dos casos de violência contra a mulher, conforme dados desta pesquisa, corroboram achados de Deslandes et al. 6, nos quais destacam principalmente os de ortopedistas $(33,8 \%)$. Os autores também referem que, muitas vezes, as vítimas necessitaram de atendimentos em duas ou mais especialidades e chamam a atenção para a necessidade de tais profissionais estarem sensibilizados e capa- citados para o enfrentamento desse problema.

Dearwater 47 alerta para a importância das diversas especialidades médicas atuarem na prevenção da reincidência da violência doméstica, pois o setor de emergência, em muitos casos, constitui o único contato entre a vítima e o sistema de saúde. $\mathrm{O}$ autor ressalta a necessidade de se discutir o potencial papel desencadeador de atendimento e acompanhamento que diferentes profissionais podem representar diante dessa situação.

Apesar da elevada ocorrência de morbidade por lesões com instrumentos contundentes encontrada nesta pesquisa, os óbitos foram decorrentes principalmente do uso de armas brancas e de fogo, o que confirma o estudo de Reis et al. 48 que analisaram crimes cometidos contra a mulher notificados pela Delegacia de Defesa Pública de Ribeirão Preto, São Paulo, e constataram o emprego de facas (14,3\%) e revólveres (10,7\%) como os tipos de armas mais utilizadas pelos agressores. Guerra 18 também refere altas proporções de uso desses instrumentos nos casos de homicídios; segundo essa autora, tais armas são reconhecidamente mais prováveis de resultar em morte. Porém, segundo Blay 49, qualquer instrumento serve para agredir, como por exemplo, faca, ácido, madeira, ferro, além das próprias mãos. Mas, em sete de cada dez casos, o revólver é o mais usado.

\section{Conclusão}

Os tipos mais comuns de violência contra as mulheres atendidas nesses três diferentes serviços públicos se relacionam com a modalidade de serviço oferecido por cada uma dessas instituições que prestaram atendimento às vítimas. Dessa forma, nos serviços de saúde em referência, os atendimentos são motivados especialmente pela agressão física, enquanto que a violência psicológica é observada somente na ONG SOS Mulher.

A violência contra as mulheres atendidas nessas instituições atinge principalmente aquelas de 18 a 39 anos, amasiadas, de diferentes profissões, mas principalmente do lar e domésticas. É praticada principalmente pelos amásios e esposos, os quais apresentam perfil sócio-econômico e etário que se assemelha ao das vítimas. As agressões ocorrem dentro dos próprios lares, e segundo as vítimas, motivadas pelos vícios e o ciúme; a esperança de que o relacionamento conjugal melhore faz com que as mulheres permaneçam na relação violenta.

As lesões mais comuns detectadas nos atendimento do HCU e do PML são as feridas contusas que atingem freqüentemente cabeça/ 
pescoço e os membros superiores. Os casos de internação evidenciam a gravidade da violência, sendo que as especialidades da odontologia buco-maxilo-facial, ortopedia e traumatologia, e clínica médica são as que mais prestam atendimento. É necessário ressaltar a importância da sensibilização dos profissionais de saúde para o acompanhamento dessas mulheres e da notificação desses casos.

Nos atendimentos do HCU e do PML as mortes não são raras e diante da gravidade das lesões, em diversos casos, nota-se a intenção do homicídio que ocorre, principalmente, pelo uso de armas brancas e de fogo.

\section{Resumo}

Este estudo apresenta aspectos epidemiológicos e clínicos da violência contra a mulher, utilizando três fontes de dados: prontuários médicos do Hospital de Clínicas de Uberlândia, Minas Gerais, Brasil, (HCU); fichas de atendimento da ONG SOS Ação Mulher Família (ONG SOS Mulher); laudos de perícia de lesões corporais e de necropsias do Posto Médico Legal (PML). No HCU e no $P M L$, os atendimentos foram decorrentes principalmente por agressão física, não havendo alusão à violência psicológica nos prontuários médicos e nos laudos, revelando que em serviços de atenção primária à saúde esta violência é evidenciada somente em pesquisas pós-entrevistas com as vítimas. Na ONG SOS Mulher foram observadas principalmente as violências psicológica e física. Nas três fontes pesquisadas houve baixa ocorrência da violência sexual, corroborando dados da literatura que retrata a invisibilidade desta questão, principalmente da violência sexual conjugal sofrida pelas mulheres que buscam ajuda nesses serviços. Os dados da presente pesquisa permitem concluir que os tipos de violência contra a mulher nesses três diferentes serviços públicos de saúde e social, em Uberlândia, diferenciam-se conforme as características específicas dos serviços oferecidos nessas instituições.

Violência Contra a Mulher; Agressão; Serviços de Saúde
É importante salientar que o estudo em questão trata-se de demanda de serviços e não de dados populacionais, por isto, não é possível comparar os dados com outros que tratem de prevalência populacional ou fatores de risco sem levar em consideração que se refere à amostra de serviços, e diversos entre si. As variáveis sóciodemográficas das vítimas e de seus agressores têm relação com a demanda de um dos serviços, e não podem ser interpretadas ou generalizadas as características das mulheres que sofrem violência, mas apenas daquelas que buscam ajuda nessas instituições pesquisadas.

\section{Colaboradores}

M. V. Garcia, L. A. Ribeiro e M. T. Jorge participaram de todas as etapas da elaboração do artigo, desde o delineamento do estudo, a coleta e análise das informações até a redação e revisão crítica final do artigo. G. R. Pereira e A. P. Resende colaboraram na coleta e tabulação dos dados do PML e HCU e na discussão dos resultados. 


\section{Referências}

1. Andalaft Neto J. Violência sexual e interrupção da gestação prevista em lei: manual de orientação. São Paulo: Editora Ponto; 2004.

2. Ministério da Saúde. Prevenção e tratamento dos agravos resultantes da violência sexual contra mulheres e adolescentes: norma técnica. Brasília: Ministério da Saúde; 1999.

3. Barsted LAL. Uma vida sem violência: o desafio das mulheres. Observatório da cidadania 2004. http://www.socialwatch.org/es/informeImpreso/ pdfs/panorbrasileiroc2004_bra.pdf (acessado em 21/Ago/2006).

4. Secretaria Especial de Políticas para as Mulheres. Programa de prevenção, assistência e combate à violência contra a mulher - Plano nacional. Diálogos sobre a violência doméstica e de gênero: construindo políticas para as mulheres. Brasília: Secretaria Especial de Políticas para as Mulheres; 2003.

5. Giffin K. Violência de gênero, sexualidade e saúde. Cad Saúde Pública 1994; 10 Suppl 1:S146-55.

6. Deslandes SF, Gomes R, Silva CMFP. Caracterização dos casos de violência doméstica contra a mulher atendidos em dois hospitais públicos do Rio de Janeiro. Cad Saúde Pública 2000; 16:129-37.

7. Schraiber LB, D’Oliveira AFPL, França-Júnior I, Pinho AA. Violência contra a mulher: estudo em uma unidade de atenção primária à saúde. Rev Saúde Pública 2002; 36:470-7.

8. Schraiber LB, D'Oliveira AFPL, Hanada H, Figueiredo W, Couto M, Kiss L, et al. Violência vivida: a dor que não tem nome. Interface Comun Saúde Educ 2003; 6:41-54.

9. Braga MHP. O silêncio é cúmplice da violência: violência doméstica e saúde pública. http://www. geocities.yahoo.com.br/uma_menina_qualquer/ domestica.htm (acessado em 30/Jun/2005).

10. Ministério da Educação. Lei no ${ }^{\circ}$ 11.340. Cria mecanismo para coibir a violência doméstica e familiar contra a mulher, nos termos do $§ 8$ o do artigo 226 da Constituição Federal, e dá outras providências. http://www.mec.gov..br/spmu/main2.asp?Id=282 (acessado em 08/Jul/2006).

11. Miller MS. Feridas invisíveis: abuso não-físico contra mulheres. São Paulo: Editora Summus; 1999.

12. Hasselmann MH, Reichenheim ME. Adaptação transcultural da versão em português da Conflict Tactics Scales Form R (CTS-1), usada para aferir violência no casal: equivalências semânticas e de mensuração. Cad Saúde Pública 2003; 19:1083-93.

13. Adeodato VG, Carvalho RR, Siqueira VR, Souza FGM. Qualidade de vida e depressão em mulheres vítimas de seus parceiros. Rev Saúde Pública 2005; 39:108-13.

14. Minayo MCS. A difícil e lenta entrada da violência na agenda do setor saúde. Editorial. Cad Saúde Pública 2004; 20:646-7.

15. Barsted LAL. Uma vida sem violência é um direito nosso: propostas de ação contra a violência intrafamiliar no Brasil. Brasília: Comitê Interagencial de Gênero/Organização das Nações Unidas/Secretaria Nacional dos Direitos Humanos/Ministério da Justiça; 1998.
16. Carmo C, Lima L, Medeiros MA, Mendes S. A violência "invisível" contra a mulher. Pesquisa FAPESP 2001; 68 Suppl:6-7.

17. Hospital de Clínicas de Uberlândia, Universidade Federal de Uberlândia. Histórico 2003. http:// www.hc.ufu.br (acessado em 12/Fev/2006).

18. Guerra CC. Ei tá violência conjugal e familiar nossa de cada dia. Dados levantados nos prontuários do S.O.S. Mulher/Família de Uberlândia. Gênero em Pesquisa 2000; (15):4-5.

19. Galvão EF, Andrade SM. Violência contra a mulher: análise de casos atendidos em serviço de atenção à mulher em município do Sul do Brasil. Saúde Soc 2004; 13:88-99.

20. Schumacher JA, Leonard KE. Husband's and wive's marital adjustment, verbal aggression, and physical aggression as longitudinal predictors of physical aggression early marriage. J Consult Clin Psychol 2005; 73:28-37.

21. Drezett JF. Estudos de fatores relacionados com a violência sexual contra crianças, adolescentes e mulheres adultas [Tese de Doutorado]. São Paulo: Centro de Referência da Saúde da Mulher e de Nutrição, Alimentação e Desenvolvimento Infantil; 2000.

22. Mattar R, Abrahão AR, Andalaft Neto J, Colas OR, Schroeder I, Machado SJR, et al. Assistência multiprofissional à vítima de violência sexual: a experiência da Universidade Federal de São Paulo. Cad Saúde Pública 2007; 23:459-64.

23. Oshikata CT, Bedone AJ, Faúndes A. Atendimento de emergência a mulheres que sofreram violência sexual: características das mulheres e resultados até seis meses pós-agressão. Cad Saúde Pública 2005; 21:192-9.

24. Dantas-Berger SM, Giffin K. A violência nas relações de conjugalidade: invisibilidade e banalização da violência sexual? Cad Saúde Pública 2005; 21:417-25.

25. Diniz SG, D'Oliveira AF. Gender violence and reproductive health. Int J Gynaecol Obstet 1998; 63 Suppl 1:S33-42.

26. Saffioti HIB, Almeida SS. Cidade maravilhosa: a outra face. In: Saffioti HIB, Almeida SS, organizador. Violência de gênero: poder e impotência. Rio de Janeiro: Editora Revinter; 1995. p. 29-55.

27. Guerra CC. Descortinando o poder e a violência nas relações de gênero: Uberlândia-MG [Dissertação de Mestrado]. São Paulo: Faculdade de Filosofia, Letras e Ciências Humanas, Universidade de São Paulo; 1998.

28. Marques TM, Pinto Júnior H. A relação entre violência contra a mulher e sua história de vida. Texto \& Contexto Enferm 1999; 8:3269.

29. Marques TM. Violência conjugal: estudo sobre a permanência da mulher em relacionamentos abusivos [Dissertação de Mestrado]. Uberlândia: Universidade Federal de Uberlândia; 2005.

30. Porto MFS. Violência e conivência: apontamentos acerca dos crimes contra as mulheres. Gênero em Pesquisa 2000; (15):18-22. 
31. Kronbauer JFD, Meneghel SN. Perfil da violência de gênero perpetrada por companheiro. Rev Saúde Pública 2005; 39:695-701.

32. Sant'Anna ME. Violência doméstica. Med Soc 2003; 16:25-8.

33. Heise L. Gender-based abuse: the global epidemic. Cad Saúde Pública 1994; 10 Suppl 1:S135-45.

34. Schraiber LB, D’Oliveira AFPL, França-Júnior I, Diniz S, Portella AP, Ludermir AB, et al. Prevalência da violência contra a mulher por parceiro íntimo em regiões do Brasil. Rev Saúde Pública 2007; 41:797-807.

35. Saffiot HIB. Gênero, patriarcado, violência. São Paulo: Fundação Perseu Abramo; 2004.

36. Noronha CV, Daltro ME. A violência masculina é dirigida para Eva ou Maria? Cad Saúde Pública 1991; 7: 215-31.

37. Schraiber LB, D'Oliveira AFPL, Couto MT, Hanada H, Kiss LB, Durand JG, et al. Violência contra mulheres entre usuárias de serviços públicos de saúde da Grande São Paulo. Rev Saúde Pública 2007; 41:359-67.

38. Ramírez-Rodríguez JC, Patiño-Guerra MC. Mujeres de Guadalajara y violencia doméstica: resultados de un estudio piloto. Cad Saúde Pública 1996; 12:405-9.

39. Heise L, Ellsberg M, Gottemoeller M. Ending violence against women. Popul Rep L 1999; 27:1-43.

40. Silva JA, Santos Júnior R, De-Sousa RA. Violência contra a mulher: aspectos psicológicos e culturais. Gênero em Pesquisa 2000; (16):19-21.

41. Saffioti HIB. No fio da navalha: violência contra crianças e adolescentes no Brasil atual. In: Madeira FR, organizador. Quem mandou nascer mulher? Estudos sobre crianças e adolescentes pobres no Brasil. Rio de Janeiro: Edições Record/Editora Rosa dos Tempos; 1997. p. 135-211.
42. Cardoso NMB. Mulheres em situação de violência conjugal: incidência, conceitos, fatores associados e conseqüências da violência. Barbarói 1996; (4/5):69-80.

43. Day VP, Telles LEB, Zoratto PH, Azambuja MRF, Machado DA, Silveira MB, et al. Violência doméstica e suas diferentes manifestações. Rev Psiquiatr Rio Gd Sul 2003; 25 Suppl 1:9-21.

44. Garbin CAS, Garbin AJI, Dossi AP, Dossi MO. Violência doméstica: análise das lesões em mulheres. Cad Saúde Pública 2006; 22:2567-73.

45. Chrcanovic BR, Freire-Maia B, Souza LN, Araújo VO, Abreu MH. Facial fractures: a 1-year retrospective study in a hospital in Belo Horizonte. Braz Oral Res 2004; 18:322-8.

46. Rezende EJC, Araújo TM, Moraes MAS, Santana JSS, Radicchi R. Lesões buco-dentais em mulheres em situação de violência: um estudo piloto de casos periciados no IML de Belo Horizonte, MG. Rev Bras Epidemiol 2007; 10:202-14.

47. Dearwater LL. Preventing injuries from violence towards women. Am J Public Health 1998; 86:12-4.

48. Reis JN, Martin CCS, Ferriani MGC. Mulheres vítimas de violência sexual: meios coercitivos e produção de lesões não-genitais. Cad Saúde Pública 2004; 20:465-73.

49. Blay EA. Violência contra a mulher e políticas públicas. Estud Av 2003; 17:87-98.

Recebido em 06/Nov/2007

Versão final reapresentada em 28/Jan/2008

Aprovado em 03/Abr/2008 